\title{
VITAL STATISTICS OF ENGLAND AND WALES
}

$\mathrm{T}$ HE two volumes of tables for $1960^{1,2}$, and the commentary for $1959^{3}$, which the Registrar General issues annually, provide the opportunity for an assessment of the position relating to the population of England and Wales. There are no important changes in the presentation of the statistics, but in the commentary there is one major innovation in the section on mortality. In place of the customary detailed review of mortality by cause of death, there is now a general section dealing with the salient features of mortality, followed by notes on selected special topics; those selected in 1959 being mortality by marital status and deaths from congenital malformation.

Mortality in general continued to decline. One of the principal features of mortality in the 1950's has been the relative stickiness of the death-rates of men over 45 compared with those of women. The following figures illustrate the position, and show that the death-rate of men aged $55-64$ is now more than double that of women of the same age:

\begin{tabular}{lrrrrr} 
& & \multicolumn{2}{c}{$1948-50$} & \multicolumn{2}{c}{$1958-60$} \\
Deaths per 1,000 & $45-54$ & $8 \cdot 3$ & $5 \cdot 3$ & $7 \cdot 3$ & $4 \cdot 4$ \\
population & $\mathbf{5 5 - 6 5}$ & $22 \cdot 3$ & $19 \cdot 5$ & $21 \cdot 7$ & $\mathbf{1 0} \cdot 8$ \\
aged & $\mathbf{6 5 - 7 4}$ & $\mathbf{5 1} \cdot 8$ & $\mathbf{3 4} \cdot \mathbf{1}$ & $\mathbf{5 3} \cdot \mathbf{5}$ & $\mathbf{3 0 \cdot 3}$
\end{tabular}

Considerable reduction in the mortality from par. ticular causes has been achieved; thus, mortality from tuberculosis has fallen by two-thirds for men, and four-fifths for women in the decade. The growth in mortality from lung cancer in the same period which has increased by 50 per cent for men and 25 per cent for women has already been widely commented on.

The interesting feature of the nineteen-fifties, however, is the behaviour of the birth-rate and of fertility. After the peak of births in 1947, when there were 881,000 live births, the number fell to 668,000 in 1955 , but this was followed by an upturn, and from 1955 the number has risen steadily to 785,000 in 1960 , a figure which (except for 1947) has not been surpassed since 1921. In his commentary on the 1959 data, the Registrar General still does not commit himself, however, on the question whether this increase in the number of births is a reflexion of an upward trend in family size or of a merely temporary change in the timing of births within marriage. Whichever is true, the rise in the absolute number of births will, of course, result in stresses on the educational system in the late nineteen-sixties and the nineteen-seventies.

It is clear that there is at present no prospect of population growth ceasing, and the projections in the 1960 Population Tables are based on the assumption that after an annual figure of 750,000 births in 1960 65 , this figure will gradually rise to 925,000 by the end of the century, and that the population will by that time have reached a figure of $55 \cdot 6$ millionsan increase of nearly 10 million in 40 years. These figures make it all the more important to carry on research into the social and economic factors associated with reproduction. Now that practically all married couples use some form of family planning at some stage of their marriage, predictions about the numbers of future births must take much more account of these factors, if they are to be at all realistic.

E. GrebenIK

\footnotetext{
'General Register Office. The Registrar General's Statistical Review of England and Wales for the year 1960. Part 1: Tables, Medical. Pp. $\mathrm{x}+332$. (London: H.M.S.O., 1962.) 22s. 6d. net.

${ }^{2}$ General Register Office. The Registrar General's Statistical Review of England and Wales for the year 1960. Part 2: Tables, Population. Pp. xi+180. (London: H.M.S.O., 1962.) 12s. 6d. net.

${ }^{3}$ General Register Office. The Registrar General's Statistical Review of England and Wales for the year 1959 Part 3 : Commentary. Pf England and Wales for the year 1959., Part 3: Com
}

\section{THE AMERICAN SCIENTIST}

$\mathrm{T}$ HE March 1962 number of the American Scientist, besides celebrating its fiftieth year of publication, celebrates the seventy-fifth jubilee of the Society of the Sigma XI. The president of the Society, Dr. W. R. Brode, contributes a long article discussing the growth of science, as measured in terms of manpower, financial support and facilities, and the implications of a national science programme in terms of changing sources of support and in responsibility for administration and planning. Dr. Brode's comments on the production of publications, the expansion of professional organizations and on the effects of the growth of science on supporting and performing institutions are of wide interest. An article by Dr. E. R. Weidlein, entitled "Co-operation -a Responsibility of the Scientist", starting with the development of the Mellon Institute, reviews the growth of co-operative research in the past half-century.

These two general articles are followed by a series of articles looking to the future of particular fields of science. Prof. G. G. Simpson in "The Status of the Study of Organisms" and Prof. C. Grobstein in "Levels and Ontogeny" look to the future of biology. Prof. S. C. Brown in "Plasma Physics" considers the potentialities of controlled thermonuclear reactions as sources of energy for peaceful purposes. Dr. N. B. Hannay writes on "Chemical Equilibria and Reactions in Semiconductors", Prof. M. Ryle on "Radioastronomy and Cosmology", including the steadystate theory, and Dr. E. M. Shoemaker describes the geologist's ideas on the exploration of the Moon's surface. Prof. R. G. W. Norrish contributes, under the title "Kinetic Spectroscopy and Flash Photolysis", a summary of his presidential address to Section B at the meeting of the British Association for the Advancement of Science at Norwich last year; J. R. Fresco and D. B. Straus describe the production of synthetic nucleotides as models of the naturally occurring nucleic acids, and Dr. C. D. Cone, jun., the thermal soaring of birds. S. Brunauer contributes an article, "Tobormorite Gel--the Heart of Concrete", and H. M. Wormington a "Survey of Early American Prehistory", while, under the title "European Scientists at Work, 1961", Dr. S. Marcson describes a visit to the Department of Scientific and Industrial Research, to the Philips Research Laboratories at Eindhoven, and to the French Petroleum Institute, Malmaison. 